\title{
Dengue hemorrágico en el niño
}

- Hospital Universitório Pediátrico del Cerro, Havana, Cuba

"* Policlínico Angel Almejeiras, Havana, Cuba

* *Hospital Pediátrico Pedro Borras, Havana, Cuba

***Hospital Pediátrico William Soler, Havana, Cuba
* Carlos Dotres Martinez

Gladys Fallat Machado

**Manuel Rojo Concepción. Miriam Aliño Santiago

**** Eric Martinez Torres
A thorough revision on hemorragic dengue fever is presented. Dengue, an acu te mosquito-borne infectious disease has occurred in epidemic form in Cuba 1981, causing death of 158 persons. The disease in its classical form was first reported in 1823 but in 1953 a new presentation charachterized by hemorrhagic manifestations, shock and a high mortality was observed in Manila, Phillipines. This form was called Hemorrhagic Dengue Fever and Dengue Shock Syndrome (HDF/DSS). Its pathogenesis can be explained by two different theories: it could be a primary infection or a hipersensibility reaction depending on a previous infection.

\section{"DENGUE HEMORRẢGICA NA CRIANÇA"}

Foi realizada uma revisão completa da Dengue Hemorrágica, doença infecciosa viral aguda e potencialmente, grave, transmitida por mosquito, que, em 1981 , causou a morte de 1.58 pessoas durante uma epidemia em Cuba, sendo 101 menores de 15 anos.

A Dengue, em sua forma clássica (benigna), foi prime iramente referida eln 1823, porém,no ano de 19.53 . em Manila, Filipinas, se registrou uma nova apresentaçäo da doença, caracterizada por manifestações hemorrágicas, choque e alta mortalidade que se denominou Febre Hemorrágica Dengue e Sindrome de Choque por Dengue (FHD/SSD). Sua patogenia é apresentada, discutindo-se também a possibilidade de repetiçăo do fenômeno nas Américas.

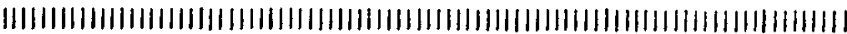

\section{CONCEPTO}

Es una enfermedad aguda, infecciosa y grave, transmitida por mosquitos y producida por virus, la cual afecta 
principalmente a los niños y se presenta fundamentalmente en áreas urbanas de las zonas tropicales aunque también se aprecia en el campo y en las selvas, que se caracteriza por permeabilidad vascular anormal, hipovolemia, hemoconcentración y diátesis hemorrágica; siendo parte intrínseca de la enfermedad, fenómenos que toman un curso más grave en algunos enfermos condicionando la aparición del llamado Síndrome de Shock el que puede o no ser reversible constituyendo el estado más critico de la evolución natural de la entidad, cuya patogenia aún no es bien conocida. $1,25,28,29,37,41,58$

\section{HISTORIA}

El origen del dengue se remonta al año 1823 , donde esclavos procedentes de Africa Occidental introdujerou en América los términos dinga o dyenga ${ }^{53}$ con la que se nombró una epidemia de la enfermedad producida en su tierra natal $1^{5,53}$ y que posteriormente fue transformada a la expresión española originando el sustantivo "dengue", asegurándose además el origen Swahili "Ki-denga-pepo" (ataque repentino parecido a un calambre o estremecimiento provocado por un espíritu malo), con precedentes en epidemias en Jakarta en 1779 y fiebre quebrantahuesos de Filadelfia en $1790 .{ }^{25}$

Este hecho histórico demuestra que la existencia de los virus dengue, datan de varios siglos; sin embargo no es hasta 1953 en Manila, Filipinas que se reconoce una nueva enfermedad que afecta fundamentalmente a los niños, caracterizada por manifestaciones hemorrágicas, shock y alta mortalidad, denominándose Fiebre Hemorrágica Filipina, con el objetivo de diferenciarla de otras enfermedades hemorrágicas que estaban ocurriendo en Corea, ${ }^{32}$ con el antecedente de reportes en Taiwan de manifestaciones hemorrágicas $y$ shock en pacientes portadores de dengue. ${ }^{10,26}$ Después de la epidemia Filipina de 1954, subsecuentemente se producen epidemias en Tailandia (1958) y Singapur (1960). ${ }^{40}$

En Bangkok corriendo el año 1958, comienzan a presentarse casos con la sintomatologia de dengue hemorrágico, produciéndose la explosión de una epidemia. El Rey de Tailandia, pide ayuda y plantea que parece tratarse de un brote de la enfermedad ocurrida en Filipinas. El aislamiento del virus dengue fue efectuado, confirmándose lo que habia sido supuesto. ${ }^{32}$

Como puede apreciarse esta terrible enfermedad se propagó gradualmente a varios países de las regiones de Asia 
Sudoriental y del Pacífico Occidental, donde ha producido grandes estragos en términos de morbilidad y mortalidad. La importancia de los efectos se puede apreciar teniendo en cuenta que durante el periodo de 1956-1979 hubo en esa Región del mundo más de 250,000 hospitalizados ycasi 12,000 fallecidos fundamentalmente niños. ${ }^{40,48}$ La histo. ria ha demostrado que la enfermedad se ha propagado de un país a otro en término de 3 a 5 años.

En el año 1981 surge en Cuba un cuadro caracterizado por fiebre, hemorragias, hemoconcentración y shock el cual afecta a cerca de 110,000 personas produciéndose 158 fallecidos, tratándose de la primera epidemia de Den. gue hemorrágico de las Américas en este siglo; epidemia causada por el virus tipo II del dengue que penetró en el País de forma extraña y con características de ser muy virulento; la epidemia cubana es la primera que se elimina en 3 meses aproximadamente ya que el Dengue Hemorrágico permanece endémico en todos los países del mundo que lo han padecido. ${ }^{40}$

No se ha reportado en Cuba ningún otro caso de Dengue Hemorrágico después de $19811^{7,8,18}$ Esta epidemia cubana ha constituído una gran preocupación para los Organismos Internacionales de Salud, ante la posibilidad de que la enfermedad se propague a otras zonas de la América donde existan condiciones favorables para su aparición. ${ }^{48}$

\section{ETIOLOGIA}

Existen cuatro tipos de virus dengue descritos en la actualidad, son pequeños virus RNA con propiedades antigénicas diferentes. Cualquiera de los cuatro tipos del virus dengue, produce un dengue clásico, pero esta primo infección según se plantea, ${ }^{28,29,56}$ crea las condiciones inmu. nológicas para que una infectión subsecuente produzca un Dengue hemorrágico; por otra parte algunos plantean que la primo infección por dengue se capaz de producir Dengue Hemorrágico. ${ }^{10,17,32,34,54}$

Los virus causantes del dengue pertenecen a los arbovirus, también conocidos como virus arbo, o virus trans. mitidos por artrópodos. ${ }^{35}$

En 1945 se aislaron los dos primeros serotipos ${ }^{6}$ y en 1956 los tipos 3 y $4 .^{6,32}$ Dentro de cada serotipo, existen cepas diferentes. ${ }^{25,52}$ El virus tipo 2 es el más inmunogénico de los conocidos. ${ }^{28}$ 


\section{EPIDEMIOLOGIA}

La infección por virus dengue, se transmite al hombre a través de la picada de varias especies de mosquitos Aedes dentro de las cuales es su fundamental vector el mosquito Aedes aegvpti el cual tiene un habitat doméstico, que se encuentra distribuído mundialmente. ${ }^{11,21,58,59}$ Es de tamaño mediano y color oscuro, con franjas en el tórax,en forma de lira y anillos blancos en las patas, lo que los diferencia de otras especies de aëdes. Es un mosquito esencialmente doméstico, los machos se alimentan de jugos vegetales, siendo la hembra la que pica, ya que necesita de la sangre para tintos au tores. En la epidemia cubana, la mayor incidencia de la enfermedad se produjo en las edades de 5 a 10 años, para aproximadamente un 50\% de los casos. ${ }^{1,39,48,50,51}$ Sobre el sexo, se ha planteado que no existe predominancia de uno sobre el otro. ${ }^{39,51}$ Sin embargo el análisis de casos fatales $y$ de shock definidos etiológica $y$ fisiologicamente muestran aumento en dependencia de la edad en el numero de niñas por el Síndrome de Shock por dengue (SSD). ${ }^{17,25}$ En relación a laraza, se ha descrito durante la epidemia cubana um franco predominio de pacientes considerados como blancos. ${ }^{39,48,50,51}$ Según evidencias de cada país en los que se ha informado la FHD endémica. hay fuerte asociación entre el estado nutricional bueno en los niños y un riesgo mayor de desarrollo de $\mathrm{SSD}^{25}$ en Cuba se evidenció que la mayor gravedad de la enfermedad se desar. rolló en niños con buen estado nutricional. ${ }^{1,39,40,50,51}$

\section{PATOGENIA}

En general los autores se han colocado en una de dos tendencias fundamentales: un grupo ha abogado por la fiebre hemorrágica dengue como expresión de la infección primaria ${ }^{10,17,32,34,54}$ mientras que el otro defiende $y$ argumenta la existencia de sensibilización previa. ${ }^{28,29,56}$

Se han planteado hipótesis en relación a la posibilidad de mutaciones o inestabilidad genética de los virus dengue que hayan propiciado el surgimiento de una cepa hemorrágica, cambios en la patogenicidad de los virus ${ }^{32}$ así como la posible existencia de variantes en la cadena de transmisión que conduzcan a un aumento de la patogenicidad para el hombre. ${ }^{20,28}$

Se señalan así mismo probables cambios en poblaciones de mosquitos que conlleven al aumento de la virulencia del virus. ${ }^{2}$ 
Existem hipótesis que se refieren a la circulación simultánea de diferentes ser otipos del virus dengue en la producción de la FHD al existir la possibilidad de que un mosquito se infectara con dos virus diferentes, inoculando al hombres con ambos a la vez ${ }^{32}$ sin embargo, se ha demostrado la supresión de la multiplicación viral al producirse la infec. ción en las circunstancias señaladas ${ }^{31}$ habiéndose reportado la transmisión simultánea de virus 1,2 y 4 sin que se produjera FHD. ${ }^{14}$

Halstead propuso en 1967 la teoría de la doble infección que se fundamentó en la existencia de dos infec. ciones secuenciales provocando fiebre hemorrágica por dengue y síndrome de shock. ${ }^{28}$ Una primera infección sensibilizaría y una segunda por un serótipo diferente en un lapso mínimo de 3 a 6 semanas y máximo de 5 años desencadenaría la fiebre hemorrágica por dengue. ${ }^{28,45}$

Estudios posteriores efectuados por el autor, en los que confirmó fiebre hemorrágica por dengue ne lactantes que sufrían infección primaria, pero que eran hijos de mujeres con inmunidad al dengue, lo hicieron modificar el nombre de su teoría. Aceptando que los anticuerpos también podían adquirirse por vía transplacentaria, la nombró . Teoría inmunopatológica. ${ }^{28}$ Esta se basa en la existencia de aticuerpos dengue del tipo IGG en cantidades subneutralizadoras, en el momento en que se produce la inoculación en el organismo de un virus dengue diferente del que estimuló la formación de esos anticuerpos. ${ }^{28} \mathrm{~A}$ estos anticuerpos se atribuyen dos funciones fundamentales $^{14}$ que por su interés patogénico y fisiopatológico serán reseñadas individualmente.

Nos referiremos primero a la formación de inmunocomplejos. Algunos autores, aunque consideran de valor la segunda función de los inmunocomplejos que posteriormente detallaremos, atribuyen su significación notable en los mecanismos de producción de la enfermedad a la capacidad que estos tienen de activar el complemento y la coagulación sanguínea. ${ }^{56} \mathrm{Al}$ activarse el sistema del complemento (por la vía clásica) fragmentos biologicamente activos, de éste, como son el C3a y C5a (anafilotoxinas) provocarían un aumento en la permeabilidad vascular ${ }^{49,55,56}$ que permitiría el escape de líquidos, electrolitos, proteínas y en algunos casos hematíes, favoreciendo la hipovolemia, la hemoconcentración y el consiguiente estado de shock; la activación del sistema de la quinina (discutida por algunos), ${ }^{25}$ pudiera sumarse como factor que incrementara esta anormal permeabilidad de los vasos. ${ }^{49}$ Edelman en sus estu- 
dios no pudo demostrar que este sistema estuviese involucrado. ${ }^{15}$

El hecho de que no se hayan demostrado lesiones destructivas del endotelio vascular hace sospechar que el aumento de la permeabilidad vascular es el resultado de la acción de sustancias farmacologicamente activas. ${ }^{45}$

La coagulación sanguínea se activaría por la capacidad que pose en los inmunocomplejos de favorecer la agregación plaquetaria y de actuar sobre el factor XII. ${ }^{49} \mathrm{La}$ activación del factor Hageman conduciría a un consumo de plaquetas por coagulación intravascular diseminada. ${ }^{56}$

Los dos últimos fenómenos serían responsables de la trombocitopenia observada en el curso de la enfermedad y determinarían la existencia de fenómenos hemorrágicos. Se ha señalado también un trastorno en las funciones plaquetarias. El daño hepático asociado propiciaria la depleción de los factores II, IX, X y XI, y contribuiría al cuadro hemorrágico, que a su vez puede llevar al shock oligohémico. 56

Una segunda función de los anticuerpos sería la de unirse al antigeno viral formando inmunocomplejos que pueden desempeñar las funciones ya reseñadas, pero que fundamentalmente servirían como facilitadores de la internalización de los virus dengue en los fagocitos mononucle ares. ${ }^{28}$

Se plantea que en la superficie de estas células, existente un receptor FC para esos inmunocomplejos, en ausencia del anticuerpo los virus dengue no lograrian una efectiva infección del monocito. ${ }^{25}$

Estas conclusiones se han basado en la demostración de que las células de la estirpe fagocitaria son los sitios principales de replicación del virus dengue en el hombre $y$ que ésta es favorecida por los hechos anteriormente expuestos. $^{28}$

Estudios experimentales con monos Rhesus utilizando dos métodos diferentes han argumentado la hipótesis propuesta. $^{25,28}$

A un grupo de monos se les ha inyectado sueros que contienen anticuerpos dengue y posteriormente se les ha inoculado un serotipo dengue para el que el anticuerpo no es especifico. A otro se le ha expuesto a dos infecciones 
secuenciales heterotípicas, y se ha tomado un grupo control al que solamente se inoculó un serotipo viral. El resultado de las experimentaciones ha corroborado la amplificación notable de la replicación viral en los dos primeros grupos, respecto al grupo control. ${ }^{25,28}$

Estudios in vitro han arrojado idénticos resultados. ${ }^{28}$ El virus utilizado en estas pruebas ha sido el tipo $2,{ }^{28}$ al que se atribuye una mayor afinidad por los anticuerpos heterólogos. ${ }^{32}$ una mayor capacidad inmunogénica y una más rápida y fácil replicación. ${ }^{28}$ Ello explicaría su más frecuente asociación con fiebre hemorrágica por dengue y síndrome de shock. ${ }^{28}$

Partiendo de los conocimientos hasta aqui expuestos estamos en condiciones de profundizar en ciertos aspectos de la inmunopatogenesis de la enfermedad que pretendemos conocer.

Una mayor replicación en los fagocitos mononucleares conduciría al aumento de la viremia y migración de los antígenos virales a otros tejidos por los que tienen afinidad, como son la médula ósea, el hígado, el bazo, los ganglios lingáticos y los histiocitos (especialmente de la piel). En ellos a su vez se replicariam incrementándose aún más la cantidad de virus circulantes y el número de células infectadas. Es lógico suponer que estos acontecimientos ejercerán un efecto nocivo sobre el huésped. ${ }^{28}$

Otro aspecto fundamental de esta hipótesis es la activación del monocito infectado, la cual se ha pretendido explicar por diferentes vias. ${ }^{25}$ Así se ha considerado el sistema de la quinina, al complemento, a los inmunocom. plejos circulantes $y$ a la respuesta de eliminación inmune dirigida contra las células hospederas del antigeno viral. ${ }^{25,28}$

Se sabe que la capacidad inmunológica es regida por factores genéticos y nutricionales, ello explicaría que la fiebre hemorrágica por dengue y el síndrome de shock sean más frecuentes en el sexo femenino y en individuos bien nutridos. ${ }^{25}$

Sea cual fuere el o los mecanismos que desencadenam la activación de los fagocitos mononucleares, uma vez ocurrida se produce la liberación por parte de estas células de sustancias vasoactivas, tromboplásticas y de enzimas activadoras del sistema del complemento, por la vía alterna. ${ }^{28,55}$ 
Las primeras provocarían aumento de la permeabilidad vascular con las consecuencias que ya fueron explicadas al tratar este aspecto en consideraciones anteriores. Se producirían igualmente hipovolemia, hemoconcentración $y$ shock e seguir progresando el cuadro. ${ }^{25,28}$ Enzimas liberadas por los monocitos actuarian sobre la fracción C3 del complemento fragmentándola en C3a y C3b. El C3a sabemos que tiene actividad citolítica, El C3b es capaz de activar el monocito, este fragmento además, se une al factor $\mathrm{B}$ formando una enzima que actúa sobre $\mathrm{C} 3$, el que por esta vía también es fragmentado. Vemos que $\mathrm{C} 3 \mathrm{~b}$ se autogenera, las sustancias tromboplásticas de los monocitos convierten el fibrinógeno en fibrina y favoreceu la coagulación intravascular diseminada que termina en la aparición de fenómenos hemorrágicos. ${ }^{25,28}$

Trabajos muy recientes reconsideran y profundizan en esta teoría.

Se plantea que el curso de la infección por virus dengue en el hombre puede estar condicionado por fenómenos de amplificación o de neutralización, determinados por la actividad de los anticuerpos. ${ }^{29}$

Considerando que existan entre las cepas de virus dengue determinantes antigénicas especificas por grupos $y$ por tipos se comprende que anticuerpos dirigidos contra determinantes por tipo, neutralizarían. en tanto que aquellos que se dirigen a las determinantes por grupos amplificarían.

Por tanto si hay suficiente anticuerpos para lograr neutralización, ésta se produce, no ocurriendo la amplifi. cación. ${ }^{29}$

Halstead propone añadir a las ya conocidas reacciones alérgicas una que involucra a anticuerpos $\lg G$, fagocitos mononucleares y un organismo que pueda parasitar a este último. Resalta que para que se produzca la fiebre hemorrágica por dengue el anticuerpo debe unirse al virus, pero no destruirlo, to cual es perfectamente posible siempre que existan cepas de virus estrechamente relacionadas o cuando los anticuerpos aumentan "para virus quimicamente altera$\operatorname{dos}{ }^{* 29}$

La importancia de los estudios moleculares en la comprensión de los fenómenos que tienen lugar en infecciones virales, debe ser altamente valoricada. 
El tema de la patogenia de la fiebre hemorrágica por dengue y el síndrome de shock, aún no se ha concluido. Queda a la sagacidad y empeño de los cient íficos contemporáneos permitir la definición exacta de los mecanismos que originan esta afección.

\section{CUADRO CLINICO}

El cuadro clínico de esta enfermedad y la presentación de las diversas manifestaciones y complicaciones, varía en ocasiones de un enfermo a otro. Las experiencias clínicas en la FHD y el SSD se han funda. mentado en lo reportado en epidemias del sudeste de Asia ${ }^{40}$ y más recientemente en la experiencia de la epidemia cuba. na de $19811^{13,39,50,51}$

Por lo general, después de un período de incubacion de entre cinco y ocho días y el antecedente de una afección anterior por virus dengue en un período no mayor de 3 a 5 años, se presenta un cuadro clínico inicialmente indistinguible al dengue clássico caracterizado por fiebre que se presenta en el $100 \%$ de los enfermos, ${ }^{40}$ mientras en la epidemia cubana ofrecen porcientos de alrededor del $99 \%$ de enfermos. ${ }^{13,39,51} \mathrm{En}$ los pacientes donde la fiebre no se constató, pude ésta haberse presentado antes del ingre. so de los enfermos. La fiebre suele ser alta ${ }^{14}$ pero no bifási. ca como clasicamente se observa en las infecciones de dengue clásico ${ }^{24,27,36}$, manteniéndose por un período de 3 a 7 dias $^{24.27}$ pos de pacientes estudiados durante la epidemia cubana. la hipetermia muestra variaciones en su pre. sentación, siendo muy frecuente un cuadro febril de 5 días con caída de la temperatura y la aprición al término de la hipertermia de hipotensión arterial, manifestaciones hemorrágicas que varían de ligeras a severas, hemorragias di. gestivas. hemoconcentración que antecede a las manifesta. ciones hemorrágicas, trombocitopenia y hepatomegalia. El período febril es acompañado de manifestaciones generales, así como rash poco intenso y fugaz $z^{13,22.23,30,39,50}$ variado en las diversas epidemias que han tendio lugar en el mundo; se ha reportado la presencia entre el 42 y $55 \%$ de los pacientes de una erupción macular, maculopapular - rubeoliforme, raramente pruriginosa y de pocos días de duración, ${ }^{39,50}$ presentándose en el $83 \%$ de los pacientes que lotuvier on del primero alcuarto día de la enfermedad. ${ }^{39}$ Otras manifestaciones que acompañan al periodo febril, han sido vómitos en más de un $70 \%$ de los enfermos. astenia en el $49 \%$, cefalea en el $43 \%$ y dolor abdominal en el $43 \%^{50,51}$ siendo estos sintomas los que se consideran más frecuentes en la literatura médica. ${ }^{19,25,50,51,53}$ 
Las manifestaciones hemorrágicas varían en cuantía, localización y cronología. ${ }^{14,42,53}$ Los fenómenos hemorrágicos se presentan en cualquier momento de la enfermedad, coincidiendo en algunos casos con el debut mientras que en otros aparece más tardiamente, no obstante la mayor parte de los pacientes exhiben algún tipo de sangramiento entre el tercer o quinto días. ${ }^{14,37}$ En algunas oportunidades se evidencia el trastorno exclusivamente al practicar la prueba del torniquete. ${ }^{37,40}$

Las manifestaciones hemorrágicas pueden aparecer en el período febril o después de éste. ${ }^{14,25}$

Durante la epidemia cubana, fluctuaron las manifestaciones hemorrágicas en grupos de niños estudiados. En pacientes del Hospital William Soler, se presentó en el $57 \%$ de los pacientes de los cuales el $16 \%$ fueron sangramientos digestivos, ${ }^{39}$ en el Hospital Pedro Borrás se presentó sangramiento en el $61,4 \%$ siendo la mayoría leves, y graves el $8,8 \%$ dados por hematemesis y enterorragias. ${ }^{50,51}$ En el grupo estudiado de la Ciudad de los Pioneros José Martí donde fueron tratados con Interferón, no se registraron casos con hemorragias moderadas o severas. ${ }^{13}$ En todas las muestras el $100 \%$ de la prueba del lazo fue positiva.

En general en la FHD, las hemorragias pueden afectar parcial o totalmente un órgano o sistema, siendo las formas de presentación las víbices, equímosis, petéquias, sangra. mientos en lugares de punciones, hematemesis, melenas, epistaxis. gingivorragias, metrorragias y menos frecuentes pero más graves son las hemoptisis y hemorragias cerebrales. ${ }^{14}$ Algunos autores reportaron la existencia de hematu. rias. Las pérdidas sanguíneas considerables pueden conducir al shock hipovolémico y a la muerte. ${ }^{25,53}$

Poco después de la lisis febril $1^{25,28,42}$ y particularmente entre el segundo y cuarto día,,${ }^{9,37,53}$ un número de pacientes presentan un cuadro de fallo circulatorio que no depende de la cuantía de los sangramientos, ${ }^{14,24,37,54}$ dado por las características clínicas de hipotensión arterial con presión arterial estrecha y signos de shock, acompañado de apagamiento del tono de los ruidos cardíacos, polipnea, agobio respiratorio y alteraciones del sensorio que van desde la inquietud, la ansiedad y el letargo hasta el coma profundo. ${ }^{14,25,24,27,28}$

Este cortejo sintomático puede no ser reversible y evolucionar hasta la muerte en un período de alrededor de 6 horas, $;^{14,25}$ es el Sindrome del Shock por Dengue (SSD), 
el cual puede presentarse entre un 48 y $65 \%$ de los casos según la experiencia cubana ${ }^{39,50,51}$, el shock puede durar entre 12 y 36 horas $^{24}, 27,28,37,53$ y puede recurrir de 1 a 2 días, planteándose asimismo que este precede a las graves hemorragias gastrointestinales, ${ }^{25}$ aunque no necesariamente está relacionado con los sangramientos. ${ }^{40}$

Se presenta hepatomegalia en más del $90 \%$ de los pacientes portadores de FHD con o sin shock, siendo variable según las epidemias. ${ }^{2,3,14,17,41,57}$ Fue constante en Filipinas, en Cuba algunos reportan el $22 \%$ de los enfermos hasta el $48 \%$ en otros grupos estudiados, ${ }^{39,50,51}$ la proporción de la hepatomegalia, no guarda relación con la gravedad de la enfermedad, quedando enmarcada su duración entre dos y siete días como promedio. ${ }^{37}$

En muchas ocasiones. la salida de líquido del espacio vascular, acompañado de proteínas y electrolitos, produce colecciones de líquido en diversos sitios de la economía, pudiéndose encontrar presencia de infiltración edematosa del tejido celular subcutáneo ${ }^{53}$ y de ascitis. ${ }^{37}$ La efusión de liquidos en la cavidad pleural se ha presentado y varía desde el 10 al $50 \%$ de casos. ${ }^{13,39,43}$

La Mortalidad, por lo general es alta en esta enfermedad, fluctuando entre el 10 y el $50 \%^{58}$ aunque en Cuba fue menor que el $1 \% !^{18}$ En la convalescencia de los enfermos, pueden aparecer lipotimias, trastornos del ritmo cardíaco y otras manifestaciones: $:^{24,27}$ lo habitual en los casos que no fallecen es la recuperación rápida, no secuelar. ${ }^{19.28}$

Según la severidad de la enfermedad, la cual depende de las características clínicas, la FHD/SSD se clasifica en cuatro grados atendiendo a la sugerencia del grupo de expertos de la OMS. ${ }^{58}$

GRADO I: Fiebre acompañada por manifestaciones generales no especificas con la única manifestación hemor. rágica de una prueba de lazo positiva.

GRADO II: Al cuadro anteior (grado I) se le añaden hemorragias espontáneas en la piel y otras (epistaxis, gingivorragias).

GRADO III: Colapso circulatorio manifestado por pulso rápido y débil, con estrechamien to de la presión del pulso o diferencial ( $20 \mathrm{~mm}$. Hg o menos) o hipotensión con piel fría y pegagosa e intranquilidad. 
GRADO IV: Shook intenso con presión arterial ausente y pulso imperoeptible.

La presencia de trombocitopenia con hemoconcen. tración, suele diferenciar el Grado I y II de la FHD del dengue clásico el cual en ocasiones puede presentarse con manifestaciones hemorrágicas pero sin hemoconcentración ni trom bocitopenia.

Los grados III y IV de la FHD son los que determinan el SSD (Síndrome de Shock por Dengue).

La presencia de trombocitopenia unida a hemoconcentración, diferencian a la FHD/SSD de otras enfermeda. des. ${ }^{58}$

EXAMEN DE LABORATORIO ${ }^{1,33,39,40,50,51}$

No son frecuentemente encontradas alteraciones en la serie leucocitaria, sin embargo puede apare cer leucopenia y en ocasiones leucocitosis con linfocitosis relativa funda. mentalmente al final del periodo febril. La trombocitopenia y la hemoconcentración son alteraciones constantes, apareciendo un conteo de plaquetas por debajo de 100,000 entre el tercer y octavo día de evolución de la enfermedad. La hemoconcentración es consecuencia de la salida del plasma del espacio vascular, apareciendo una elevación encima del $45 \%$ del hematrocrito habitualmente junto con la caída de la fiebre y las plaquetas. La valoración del hematocrito es un elemento de gran valor terapéutico y pronóstico.

En casos severos pueden encontrarse alteraciones en la coagulación.

Otras alteraciones pueden ser: hipoproteinemia, hiponatremia, elevación de la transaminasa y de la urea. La acidosis metabólica puede presentarse en casos de shock prolongado.

Se han reportado cambios electrocardiográficos ${ }^{39,40}$ dados fundamentalmente por baja voltaje y cambios inespecíficos de las Ondas T y Segmento ST.

\section{DIAGNÓSTICO}

Para hacer el diagnóstico positivo de FHD/SSD. Se precisan criterios clínicos y de Laboratorio según lo expues- 
to por el grupo de expertos de la OMS y utilizado en las distintas epidemias. ${ }^{13,39,40,50}, 51,58$

\section{CRITÉRIOS CLINIICOS}

1 - Fiebre alta, continua y de aparición brusca con una duración de 2 a 7 días.

2 - Manifestaciones hemorrágicas incluyendo un Test del lazo positivo, seguido o no da petequias, equímosis, epistaxis, hematuria, melena y otros sangramientos.

3 - Hepatomegalia

4 - Shock

\section{CRITERIOS DE LABORATORIO:}

1 - Trombocitopenia: Conteo de plaquetas menor de $100,000 \times \mathrm{mm}^{3}$

2 - Hemoconcentración: Hto. elevado en $20 \%$ o más de la cifra norma. (Por encima de $45 \%$, de gran valor terapéutico y pronóstico)

Para el diagnóstico positivo de la FHD se requieren como signos obligados los dos primeros clínicos y los dos de Laboratorio. 40,58

Es indispensable un diagnóstico temprano para prevenir las severas complicaciones y la muerte.

\section{ANATOMIA PATOLÓGICA}

En general no se encuentran lesiones macroscópicas o microscópicas que expliquen la muerte, la cual puede estar relacionada con hemorragias masivas, fundamentalmente gastrointestinales e intracraneales. ${ }^{40,57}$ Se encuentran lesiones petequiales $y$ hemorragias en casi todos los tejidos incluyendo hemorragias subendocárdicas; las efusiones en las serosas y el hígado aumentado de tamaño son hallazgos ana tomo-patológicos. ${ }^{40}$

Se describen asimismo otras alteraciones anatomopatológicas frecuentes: La hepatonecrosis, miocarditis y hemorragia pulmonar, así como edema pulmonar, hígado graso e hipercelularidad glomerular ligera. ${ }^{39}$

Se han descrito lesiones reticulo endoteliales tales Cadernos de Saúde Pública, R.J. 2 (3):158-180, abr/jun, 1987 
como proliferación de células esplénicas y de ganglios linfáticos, asi como proliferación de linfocitos jóvenes $y$ células plasmáticas. ${ }^{40}$

\section{COMPLICACIONES $1,39,40, \$ 8$}

Las más serias son las grandes hemorragias y el shock irreversible que aunque son parte de la enfermedad, podrían ser hasta cierto punto prevenidas con un diagnóstico y hospitalización así como un tra tamiento oportuno.

PRONOSTICO $1,13,39,40,50,51,58$

En los países donde la enfermedad es endémica se han reportado altas cifras de mortalidad, aunque el mejor conocimiento de la fisiopatogenia y la experiencia en el manejo terapéutico han mejorado el pronóstico. Se han reportado cifras de mortalidad de entre el 10 y el $50 \%$ de los enfermos en grandes epidemias. Como es sabido, la Mortalidad por FHE/SSD, está determinada en gran parte por la acción clinica y el tratamiento. El diagnóstico precoz de la enfermedad y la pronta adaptación de medidas terapéuticas adecuadas son imprescindibles para reducir el número de victimas. $^{48}$

En Cuba durante la epidemia de 1981, se logró la más baja mortalidad reportada mundialmente por esta enferme$\operatorname{dad}^{7,8,18}$ gracias a las medidas organizativas desarrolladas para hacer frente a esta terrible epidemia, las cuales contaron con la participación yapoyo del Gobierno y de todo el pueblo, se basó fundamentalmente en la lucha contra el vector, el diagnóstico precoz, la hospitalización de todos los enfermos y el tratamiento oportuno. ${ }^{48}$

\section{TRATAMIENTO}

\section{PREVENCION:}

Para el control de brotes de FHD/SSD, se hace indispensable el control del agente transmissor del dengue, el mosquito Aedes aegypti a través de programas destinados a su control y erradicación en los países con riesgo de ser afectados. ${ }^{33,40,41,47,58}$

En relación a la prevención individual, se ha planteado el uso de medidas individuales para la protección contra la picadura del mosquito, erradicando criaderos domicilia. rios, así como la utilización de mallas milimetradas, mosquiteros, repelentes y otros. ${ }^{41,58}$ 
Aunque es factible el desarrollo de una vacuna viva, mediante alineación viral, existe el peligro del desarrollo de la FHD/SSD en caso que se utilice una vacuna tetravalente ya que al inmunizar una persona con un serotipo viral pue. de ocurrir que esta sufra una segunda infección por un serotipo diferente. ${ }^{33}$

En la reunión del Grupo técnico sobre Aedes aegypti, dengue y fiebre amarilla auspiciada por la O.P.S. en Mérida, Yucatán. México en 1982, se expresó entonces que todavía se necesitaban de cinco a ocho años para lograr vacunas eficaces contra el dengue. ${ }^{48}$

\section{TRATAMIENTO CURATIVO:}

El exito de la terapéutica una vez que se ha presentado la FHD/SSD está relacionado con la precocidad del diagnóstico así como los recursos al alcance del personal médico y paramédico y la capacidad de éste ante los casos presentados y la rapidez del proceso en muchos de ellos. no existiendo tratamiento específico para esta enfermedad, sólo medidas sintomáticas y la terapéutica con coloides, líquidos y sangre según las necesidades de los pacientes. ${ }^{40,47}$

Durante la epidemia cubana de Dengue Hemorrágico en 1981. Dotres y colaboradores, utilizaron el in terferón en un grupo de 166 pacientes portadores de dengue, de los cuales 45 presentaron FHD, en el Hospital de la Ciudad de los Pioneros José Martí en Ciudad de La Habana. El interferón cubano fue utilizado a la dosis de 30,000 a 50,000 Uds. $x \mathrm{Kg}$. de peso en el momento del diagnóstico (primer o segundo dia de fiebre) repitiendo según las necesidades dos o tres dosis. El interferón actúa interfiriendo la replicación viral dentro de la célula, determinando la detención de la multiplicación del virus y por ende la supresión del aumento de la viremia y migración de los antígenos virales a otros tejid os por los que tienen afinidad así como la reducción de la posibilidad de la unión de los anticuerpos con los antígenos virales y como consecuencia la reducción en la formación de inmunocomplejos los cuales a través de la acción directa y de la activación del complemento actuarían en las paredes vasculares aumentando su permeabilidad y desencadenando la cascada sintomática ya descrita. ${ }^{1,1325,28}$ En la muestra estudiada. no se presentaron fallecidos ní pacientes con sindrome de shock por Dengue; todos los en. fermos tratados en las primeras 18 horas de la fiebre con interferón, sólo presentaron los grados 1 y II de la FHD. ${ }^{13}$

Dentro de las medidas sintomáticas, generales y espe- 
cíficas en el manejo de pacientes portadores de FHD/SSD, tenemos las siguien tes: ${ }^{13,39,40,50,51,48}$

- Hospitalización inmediata del enfermo diagnosticado con FHD/SSD

- La fiebre alta deberá ser tratada pero nunca con salicilatos por su acción anticoagulante, así como los trastornos que ocasionan en el equilibrio ácido básico. Se recomienda medidas antipiréticas físicas así como el uso de acetaminofen o dipirona.

- Los vómitos que son otro síntoma muy frecuente en la enfermedad y que muchas veces son la antesala de la hemoconcentración, deben ser tratados precozmente: se recomienda la hidratación oral con jugos de frutas frías o las sales de rehidratación oral utilizadas para el tra tamiento de las enfermedades diarreicas. La supresión de la vía oral con hidratación parenteral estaría indicada en caso de vómitos incontrolables. El difenhidrinato. el metilbromuro de homatropina y el hidróxido de aluminio son medicamentos que suelen utilizarse como antieméticos y ante la presencia de gastrit is frecuentes en la enfermedad.

- La hemoconcentración suele presentarse entre el tercer y quinto día de evolución de la enfermedad, generaimente precedida por vómitos. deve ser tratada con hidrata. ción parenteral de solución salina físiológica, inicialmente a $400 \mathrm{cc} \mathrm{m}^{2}$ en 1.2 horas para después continuar con mante. nimiento de sol silina al $1 / 2$ a $2000 \mathrm{cc} \mathrm{m}^{2}$ durante por 4.6 horas más: si a las 8 horas continúa la hemoconcentración. se recomienda albúmina humana al $10 \%$ a razón de 6 c.c. $\mathrm{Kg}$. Si unido por a la hemoconcentración hubiese anemia, se recomienda sangre fresca a 10 c.c. $\mathrm{Kg}$. Si manifestaciones de sangramiento con trombocito por penia inferior a 30000 plaquetas. plasma rico en plaquetas $10 \mathrm{cc}$. por $\mathrm{Kg}$.

Ante manifestaciones de pre-shock, se recomienda una observación estricta del paciente. con toma sistemática de la T.A. y las mismas medidas terapéuticas planteadas en la hemoconcentración según las variantes.

Ante las efusione's pleurales. recomendamos el uso de plasma o albúmina con vistas al aumento de la presión oncótica. unido al uso de furosemida para evitar la sobrecarga liquida del espacio vascular y por ende las manifestaciones de sobrehidratacion e insuficiencia cardiaca. esta ultima medida sie nupre que no exista hemoconcentración. 
- Si se presenta shock, se recomienda el tratamiento del mismo en una unidad de terapia aunque no debe remitiroe ningún enfermo en este estado. "Las medidas deben desarrollarne donde el shock se presente". Inicialmente se recomienda hidratación com Sol. Salina a 400 por c.c. $\mathrm{m}^{2}$ sup corp. en 1 hora, continuando con $2000 \mathrm{cc} . \mathrm{m}^{2}$ las próximas 4 horas; si no sale del shock dentro de la primera hora, se recomienda el uso de Dextrán de peso me. dio $10.20 \mathrm{cc}$. $\mathrm{Kg}$ por deberá tenerse en cuenta corregir la acidosis metabólica y mantener control electrolítico. No deberá utilizarse albúmina en el shock y la sangre y plasma se valorarán según $\mathrm{Hb} . \mathrm{y}$ coagulación.

- Ante los sangramientos, se recomienda una terapéutica similar a la del pre-shock; teniendo en cuenta la hb., si ésta es menos de $7 \mathrm{gr} \%$, se recomienda uso de sangre fresca y si coagulopatía plasma fresco con o sin plaquetas en relación a la trombocitopenia. cuado.

- En caso de CIV, se recomienda su tatamiento ade-

- Ojo con la sobrehidratación e hiperelectrolitemia

- Ojo con el shock reversible

\section{ORGANIZACION DE LA ATENCION MEDICA ANTE UNA EPIDEMIA DE FHD/SSD}

Todos los paises donde se haya demostrado la actividad del dengue o exista el A. aegypti, son susceptibles de ser afectados por la FHD/SSD. ${ }^{47}$ Particularmente los paises de América Central y el Caribe están expuestos, teniendo en cuenta los antecedentes históricos de lo ocurrido en el Sudeste de Asia donde la enfermedade fue apareciendo de país en país ${ }^{40,48}$ y la epidemia cubana ocurrida en 1981 con una afección del virus tipo II y antecedentes de una epidemia em 1977.78 a dengue tipo I. ${ }^{7,8,18,48} \mathrm{La}$ casi nula experiencia de los médicos en América en los aspectos clínicos y terapéuticos de la enfermedad confiere a la O.P.S. el cometido vital de proporcionar a los $\mathrm{Pa}$ íses Membros expuestos, los conocimientos, el apoyo y los recursos necesarios para prevenir la Mortalidad por FHD/ SSD, en caso de que se produzcan nuevos brotes en el hemisferio. ${ }^{48}$ Esta ausencia en la experiencia para el manejo de cientros y miles de casos con graves manifestaciones de hemoconcentración, shock y sangramientos es uno de los principales escollos en el manejo de una epidemia de 
FHD/SSD.

La coordinación de las medidas de control de emergencia para la FHD/SSD, puede implantarse mejor a través del estabelecimiento de un Comité que incluya: Administradores, epidemiólogos, clínicos, entomólogos y represen. tantes de los laboratorios virológicos. ${ }^{4,11,21,58}$

Debe sospecharse un brote de FHD, cuando:

- Varios niños son afectados de una enfermedad febril caracterizada por fiebre de dos o más días de duración, sin respuesta al tratamiento contra la malaria. ragia o sin ella.

- Muertes inexplicables que se produzcan con hemor-

- Pacientes con petequias, epístaxis o gingivorragia, hematemesis o melena, que precedida o junto a hemoconcentración se presentaran fundamentalmente en la pobla. ción infantil. temperatura.

- Cuando aparece um cuadro de shock al caer la

Ante esta sospecha o la presencia segura de casos con FHD/SSD, deben como estrategia fundamental, llevarse a cabo simultaneamente medidas para obtener el control del vector, el diagnóstico de pacientes afectados y el tratamiento de los pacientes hospitalizados. ${ }^{33}$ Logicamente el éxito de un plan de medidas está directamente relacionado con el apoyo de los gobiernos, autoridades de salud y demás organizaciones así como el papel que juegue la población del país afectado. Por todo ello es fundamental ante toda sospecha o seguridad de una epidemia de FHD/SSD tener en cuenta los siguientes aspectos.

- Los antecedentes históricos del dengue ne el País donde se desarrolle, así como el índice de infectación por Aedes aegypti del mismo, y algo importante, la secuencia de las epidemias de dengue y el tiempo que ha mediado entre ellas, resultando lo más peligroso la secuencia de una epidemia por dengue II entre 3 meses a 5 años después una epidemia por dengue $\mathrm{I}$.

- En aquellos países donde no hay experiencia con FHD/SSD, y existen las condiciones señaladas para la posible aparición, deberá tenerse en cuenta la incansable lucha contra el vector tanto de indole masiva a través de los 
medios de difusión como de índole individual o comunitaria, regidas ambas por um programa de erradicación y control, cuya responsabilidad caerá en el Ministerio de Salud

- Se hace necesario en aquellos países que carecen de experiencia clínica y diagnóstica y que son susceptibles a epidemias, tener en cuenta dada la extrema gravedad de la situación que se tornaría en una alarma nacional, preparar al personal médico y paramédico y realizar programas de emergencia que incluyan recursos materiales, humanos y de medicamentos para una enérgica acción ante la epidemia, incluhendo la hospitalización de la casi totalidad de enfermos portadores de FHD/SSD que puede fluctuar entre el $20 \%$ y el $40 \%$ de los enfermos. Debe tenerse presente que al inicio de toda epidemia el desconocimiento para el manejo de los enfermos, produce altas cifras de mortalidad, que podrían llegar hasta el 50\% de los afectados.

- Son fundamentales, pues, los siguientes aspectos para el manejo de los pacientes:

- Control del vector.

- Conocimiento de la enfermedad.

- Diagnóstico preços fundamentalmente a través del hematocrito $y$ las características clinicas.

- Condiciones de hospitalización para proporcionar un tratamiento oportuno, adecuado, dinámico y fisiológico.

- Paralelamente a las medidas médias. debe desarrollarse dinamicamente un plan para la disminución rápida y efectiva del Aedes acgypti, utilizando incluso la fumigación aérea y todas las vías reportadas para combatir el vector de esta terrible enfermedad.

Para implementar las medidas terapéuticas seleccionadas se habilitaron como hospitales los intenados escolares de las provincias del Pais. se estableció una red de transportes para el traslado de los enfermos, se redistribuyó el personal médico y se mantuvo estrecha supervision de las actividades haciéndose los ajustes organizativos y operativos necesarios según el curso de la epidemia y la disponibilidad de camas y otros recursos. Se hospitalizó un total de 116,143 pacientes y se logró que la tasa de Mortalidad resultara notablemente más baja que la registrada en epidemias semejantes al Asia Sudoriental y del Pacífico Oc- 
cidental.

Con relación a la prevención de la Mortalidad, en la reunión del Grupo Técnico sobre Aedes aegypti, dengue y fiebre amarilla celebrada en Yucatán, México en Junio de 1982, el Dr. Francisco Pinheiro, Asesor Regional de enfermedades víricas de la O. P. S., señaló que el rol de esta Organización ante la ocurrencia de una epidemia podrá ser el de fortalecer el sistema de vigilancia en los paises susceptibles, mediante medidas que incluyen el fortalecimiento de las cadernas de laboratorios nacionales para el diagnóstico del dengue y la diseminación de información sobre diag. nóstico clínico y tratamiento de la enfermedad. Además, se podrán identificar consultores y preparar listas de medica. mentos que pueden ser utiles en caso de un brote. De ocurrir dicho borte, la OPS podría disponer de un equipo de expertos en manejo clínico y tratamiento de los pacientes, $y$ prestar ayuda en medicamentos y otros recursos necesarios. $^{48}$

\section{REFERẼNCIAS BIBLIOGRÄFICAS}

1. ALIÑN, M. et alii. Sindrome de shock por dengue, estudio clinico de 67 pacientes. Habana, 1982. (Trabajo para optar por el título de especialista de 1 ? grado en Pediatria).

2. BARNIS. W. J. S. \& ROSI:N. L. latal hemorrlagic discases and hock assoclated with primary dengue infection on a Pacific Island. Am. J. Trop. Med. Hyg., 23 (3):495, 1974.

03. BLI:SON, P. B. \& MCDIRMOTT, W. Tratado de medicina in. tema. 14. ed. México, Interamericana, 1980. t. 1, p. 284

4. BIOL.)(GIA y control del Acdes acgypti. lector Trop. (4): 1-71, 1980.

5. CARI:Y. D. I.. Chikungunya and dengue: a casc of mistaken identity? J. Hist. Mled., 26 (3):243-62, 1971.

6. CARLY. D. I. et alii. Dengue viruses from: febrile patient in Nigcria. 1964-1968. Lancet, I (7690): 105-6, 1971.

7. CASTRO RUZ, F. Discurso por la inauguración de los Congresos de Pediatria. Habana, Cuba, 11 nov. 1984. Habana, Política, 1984.

8. CASTRO RUZ, I: Discurso por el $28^{\circ}$ aniversario del A salto al Cuartel Moncada. Las Tunas, 26 jul. 1981. Habana, Política, 1981.

9. COHEN. J. N. et alii. Shock associated with dengue infection. I. Clinical and physiologic manifestations of denguc hemorhagic fever in Thailand, 1964. J. Pediat., 68: 448-56, 1966.

10. DENGUE. Br. Med. J., 2 (6096): 1175-6, 1977.

11. LL DLNGUE. Vector Trop. (2): 1-34, 1980.

12. DINNGUL: perguntas y respuestus. Rev. Cub. Pediatr., 50 (1): 95-7, 1978. 
13. DOTRES MARTINI:Z, C. et alii. Comportamicnto clinico humoral y manejo de 166 pacientes portadores de dengue en la Ciudad de Pioneros Josć Marti, Tarará. In: JORNADA NACIONAL DE PIEDIATRIA, 20. Pilar del Rio, 16-20 dic. 1981. Resumenes. s.n.t. p. 34.

14. DOURY, J. C. et alii. Dengue a forme hemorragique: Mise en evidence d'un Syndrome de Coagulopathic de Consommation. Med. Trop., 40 (2): 127, 1980.

15. EDELMAN, R. et alii. Evaluation of the plasma Kinin System in dengue hemorrhagic fever. J. Lab. Clin. Med., 86 (3):410$21,1975$.

16. FISHER, D. et alii. Observations related to pathogenesis of dengue hemorrhagic fever, $\mathrm{V}$ : examination of age specific sequential infection rates using a mathematical models. J. Biol. Med., 42 (5): 329.50, 1970.

17. l.RASES, H. S. et alii. Dengue fever in Jamaica with shock and hypocomplementacmia, hemorrhagic, visceral and neurological complications. West Indian Med.J., 27(2):106-16,1978.

18. GRANMA: Organo Oficial del Comité Central del P.C.C. Epidemia de dengue en Cuba 1981. La Habana, 1981 . p. 1-2.

19. GUZMAN TIRADO, M. G. Dengue 1: antecedentes históricos, agentes ctiológicos, quadro clínico. Rev. Cub. Med. Trop., 32 (2): 123-30, 1980.

20. GUZMAN TIRADO, M. G. Dengue I: antecedentes históricos, agentes etiológicos, quadro clínico, Rev. Cub. Med. Trop., $32(3): 191-6,1980$.

21. GUZMAN TIRADO, M. G. Dengue II: diagnóstico de laboratorio, imunidad, cpidemiologia. Ret. Cub. Med. Tropo., 32 (3): 191-6, 1980.

22. HALSTEAD, S. B. Dengue y enfermedades del tipo del dengue. In: NELSON, W. E. et alii. Nelsons tratado de pediatria. 6. cd. Barcelona, Salvat, 1975. v. 1, p. 671-3.

23. HALSTEAD, S. B. Dengue fever and dengue-line disease. In: VAUGHAN, V. C. et alii. Nelson texthook of pediatrics. 11. ed. Philadelphia, Saunders, 1979. v. 1, p. 940-8.

24. HALSTEAD, S. B. Dengue hemorrhagic fever. In: VAUGHAN, V. C. Nelson textbook of pediatric. 11. ed. Philadelphia, Saunders, 1974. v. 1. p. $942-4$.

25. HALSTEAD, S. B. Dengue hemorrhagic fevera public health problem and a field for rescarch. Bull. WHO, 58 (1): 1.21, 1980.

26. HALSTEAD, S. B. Dengue and hemorrhagic fever of Southeast Asia. Yale J. Biol. Med, 37:434-54, 1965.

27. HALSTLAD, S.aB. liebre hemorrágica del dengue. In: NI:LSON, W. E. et alii. Nelson tratado de pediatria. 6. ed. Barcclona, Salvat, 1975. v. 1, p. 673-5.

28. HALSTEAD, S. B. Immunological parameter of togavirus di. sease syndromes. The togaviruses. New York, Academica Press, 1980. cap. 5, p. 167-72.

29. HALSTEAD, S. B. The pathogenesis of denguc. Molecular epidemiology in infections disease. Am. J. Epidemiol., 114: $63248,1981$. 
30. HALSTEAD, S. B. et alii. Observations related to pathogenesis of dengue hemorrhagie fever, I: Experience with dossification of dengue viruses. Yale J. Biol. Med., 42 (5): 261-75, 1970.

31. HALSTEAD, S. B. et alii. Observations related to pathogenesis of dengue hemorrhagic fever; IV: Relation of discase severety to antibody response and virus recovered. Yale J. Biol. Med., 42 (5): 311-28, 1970.

32. HAMMON, W. D. Dengue hemorrhagic fever. Do we know its causes? Am. J. Trop. Med. Hyg., 22 (1): 82-91, 1973.

33. LA HOZ, L. M. ct alii. Estudio clinico de 202 caso de fiebre hemorrágica dengue. Habana, 1982. (Trabajo para optar por el título de cspecialista de primer grado en pediatria).

34. JAMAICA. Br. Med. $J ., l(6117): 893-4,1978$.

35. JAWETZ, E. et alii. Enfermedades por virus transmitidos por artrópodos (Arbo). In: Manual de microbiologia médica. 4. ed. Habana, Pueblo y Education, 1973.p. 375-6.

36. JOHNSON, K. M. Dengue. In: BEESON, P. B. et alii. Cecill.oeb. Tratado de medicina interna. 14. ed. Madrid, Importécnica, 1978. v. 1, p. 264.

37. JOHNSON, K. M. Fiebre hemorrágica por virus del dengue. In: BLESON, P. E. Cecil-Loeb. Tratado de medicina interna. 14. cd. Madrid, Importécnica, 1978. v. 1, p. 284-6.

38. MARTINI:Z, A. Dnguc. In: SALA GINEBREDA, J. M. ct alii. Tratado de las enfermedades infecciosas en la infancia. 2. ed. Barcelona, Científica Medica, 1962. y. 1, p. 363-4.

39. MARTINEZ TORRES, k. et alii. Dengue hemorrágico en el niño: estudio clínico-patológico. Habana, CNICM, 1984.

40. NIMANNITYA. S. Dengue hemorrhagic fever. Pediatric Practice, Thailandia (155-161).

41. ORGANIZACIÓN PANAMLRICANA DI: LA SALUD. $k 1$ control de las enfermedades transmisibles en el hombre. 11. ed. Washington, 1972. p. 123-8 (Publicación Científica, 252).

42. ORGANIZACIÓN PANAMLRICANA Dl: LA SALUD. licbre hemorrágica de las Filipinas y Asia Sudoriental. In: El control de las enfermedades transmisibles en el hombre. 12. ed. Washington, 1978. p. 120-2 (Publicación Científica, 372).

43. PACIN, R. A. et alii. Aspectos radiológicos del dengue. JORNADA NACIONAL DJ: PIDDIATRIA, 20. Pinar del Rio, 16-20, dic. 1981. Restumenes. s.n.t. p. 28.

44. PARC, F. et alii. La dengue dou viroses de type 4 in polynesic trancoisc I: epidemiologia general. Med. Trop)., 41 (1): 86-9, 1981.

45. PATHOGENETIC mechanisms in dengue hacmorrhagic fever: report of an international colluborative study. Bull. WhO, $48(1): 117-33,1973$.

46. PEDNINI, J. et alii. Iiicbre hemorrágica dengue: algunas consideraciones acerca dela prevención, control, diagnóstico y tratamiento de esta entidad. Mesa redonda, Cienfuegos, Hospital Provicincial Gustavo Aldereguía, 1981. 
47. PROPAGACIÓN de la fiebre hemorrágica dengue. Cronica OMS, $33(3): 121-2,1979$.

48. REUNION DEL GRUPO TECCNICO AEDES ALGYPTI, DENGUE Y FIEBRE AMARILLA. Mcrida, Yucatan, México, 1-5, jun. 1982.

49. ROITT, I. Hypersensitivity. In: Essential immunology. 3. ed. Oxford, Blackwell Scientific Publications, 1977. p. 151-87.

50. ROJO-CONCEPCIÓN, M. et alii. Dengue hemorrágico. Estudio clinico de 202 pacientes pediátricos. Rev. Cub. Pediatr., 54 (5): 519-38, 1982.

51. ROJO-CONCLPCION, M. et alii. Dengue hemorrágico. Estudio clínico de pacientes ingresados en un servicio. In: JORNADA NACIONALiE PLDIATRIA, 20.Pinar del Rio, 16-20, dic. 1981. Restimenes. s.n.t. p. 26.

52. RUSSILL, P. K. Informes y observaciones sobre el dengue, la fiebre amarila y la erradicación del Aedes Aegypti en las Americas. Resumen del informe sobre la tercera reunión del Comité Cientiffico Asesor de la OPS sobre el dengue. Bol. OPS. $78(3): 264 \cdot 5,1975$.

53. SCHLESINGI:R, R. W. Dengue riruses. Wien, Springer-Verlag, 1980.

54. SCOTT, R. M. et alii. Shock syndrome infections. A m. J. Trop. Med. Hyg., $25(6): 866-74.1976$.

55. SPITZlE, R. I.. I. I sistema del complenento. Clin. Pediat. Nort. $24(2): 351-74.1977$.

56. SWATTH. V. Dengue hemorrhagic fever. Hemoatological abnormalities and pathogenesis. In: Nt:W development in pediatric rescarch. New Delhi. Interprint. 1977. v. 1. p. 447.53.

57. VALCiHAN. V. C. \& MCKAY, R. J. Nelson's texthook of pediatrics. 10. ed. Philadelpha. W. B., Saunders, 1975. p. 700.

58. WORLD HI:ALTH ORGANIZATION. Technical Advisory Coinitte on Dengtu Hacmorrhagic lever for the South last Asian and Western Pacific Regions. (ivide for diagnosis, treat. ment and control of densue haemorrhagie fever. Cicnova. 1980.

59. ZINSSI'R. Dengue: viroses en el hombre transmitida por artrópodos. In: Microbiologia de Yinsser. Cuba. Rivolucionaria, 1967. t. 2. 